SCD and can occur with both infection (bacterial and viral,) and sickle cell crises. This study aimed to look at the incidence of bacteraemia and bacterial infections in children with SCD presenting to a NorthEast London district hospital with a fever of 38.5 degrees or higher.

Methods A retrospective analysis was performed on all children (aged under 16 years,) with SCD presenting with a fever of $38.5^{\circ} \mathrm{C}$ or higher over a 1-year period. Data was collected for each febrile episode on age of child, type of SCD, final clinical diagnosis, initial White cell count (WCC) and C-reactive protein (CRP) levels, blood culture and microbiology results, length of stay and clinical outcome. Children were divided into those having a definite bacterial infection, suspected bacterial infection (clinically suspected but no microbiological confirmation,) or no bacterial infection. Definite bacterial infection was defined as bacteraemia (the isolation of a non-contaminant bacterial from the blood culture,) or other bacterial infection with positive microbiological confirmation.

Results Over the 1-year period there were 88 episodes analysed in 59 children. Definite bacterial infection occurred in $8 \%$ of febrile episodes of which $3.4 \%$ had bacteraemia. (Streptococcus pneumonia, Salmonella hartford, Salmonella typhirium.) Suspected bacterial infection occurred in a further 33\% of episodes. In $59 \%$ of episodes the final diagnosis was either a sickle cell crisis or viral illness (no bacterial infection.) Diagnosis did not vary significantly by haemaglobinopathy. One death occurred from Salmonella typhirium septicaemia. Average length of stay varied from 3.6 days in the group with no bacterial infection to 8.9 days in the group with definite bacterial infection.

Conclusion Bacterial infections continue to be a significant problem in children with sickle cell disease. Salmonella infection is a growing concern in this group of children. Further work is required to identify risk factors and predictors for bacterial infection, and ascertain optimal prevention and management strategies.

\section{G186(P) AN AUDIT OF MANAGEMENT OF PAIN CRISES IN CHILDREN WITH SICKLE CELL DISEASE}

doi:10.1136/archdischild-2013-304107.198

N J Boyd. School of Medicine, University of Glasgow, Glasgow, UK

\begin{abstract}
Aims Sickle cell disease (SCD) is a lifelong haematological disorder resulting in anaemia and pain crisis. Specialist centres use experienced staff and accredited protocols to manage pain crises in affected children. The main objective of this audit is to identify areas of management of crises which could be improved in line with recommendations set out locally, by the 'Painful Sickle Cell Crisis Protocol' and nationally, by the NHS Sickle Cell disease in Childhood Standards and Guidelines for Clinical Care. This may provide useful insight for service improvement and evidence for similar units throughout the UK and Europe. Of particular interest was timing and efficacy of administration of analgesia.
\end{abstract}

Methods Baseline audit of management of patients presenting to Accident \& Emergency (A\&E) or the hospital's haematology day unit (DU) due to acute pain crisis of SCD was conducted. The study cohort was all patients seen at the hospital with a diagnosis of SCD from 1st January 2010 to 31st December 2011. 43 patients met this criteria. Re-audit to be done January 2014.

Results Of the 43 patients registered with the hospital haematology unit, 12 attended the hospital because of pain crises, whilst 31 had no pain crises within the allotted time frame. 5 patients experienced more than one acute pain crisis. Time to administer initial analgesia was $57 \pm 37$ minutes. Average length of stay in hospital was $4.5 \pm 3$ days. The most common initial analgesic administered was oral or IV morphine. 14 of the 25 children had tried medication at home prior to presenting.

Conclusions Aspects of the service identified for improvement include: clear documentation of time patient presents, time they are seen by a doctor and time they are given their first analgesia; unequivocal inclusion of a drug kardex in patients notes and consistent use of a pain scoring system.

Recommendations Implementation of a 'Sickle Cell Pain Crisis Assessment and Management' form. This would improve consistency of documentation of information relating to pain crises and therefore accuracy of future service monitoring.

\section{G187(P) CAUSES OF SEVERE ANAEMIA (HB < 5 G/DL) IN CHILDREN (<18 YEARS) BETWEEN 2006 AND 2009}

doi:10.1136/archdischild-2013-304107.199

${ }^{1} \mathrm{R}$ Sidhu, ${ }^{2} \mathrm{~K}$ McLean, ${ }^{2} \mathrm{C}$ Halsey, ${ }^{2} \mathrm{~B}$ Gibson, ${ }^{2} \mathrm{E}$ Chalmers, ${ }^{2} \mathrm{~N}$ Heaney. ${ }^{1}$ University of Glasgow, Glasgow, UK; ${ }^{2}$ Department of Haematology, Royal Hospital for Sick Children, Glasgow, UK

Severe childhood anaemia risks significant morbidity and mortality though may have different benign or malignant aetiologies. We set out to define the characteristics of this group of patients at our institution.

This study was performed in a large paediatric teaching hospital. We retrospectively identified children $(<18 \mathrm{y})$ presenting with $\mathrm{Hb}$ $<5 \mathrm{~g} / \mathrm{dL}$ in the period $2006-9$ by use of computerised laboratory records. Case notes were then reviewed and we recorded patient characteristics, final diagnosis and management with $2 y$ of follow-up.

93 patients fitted study criteria. Patients were mean age 5y, (range 1d-17y). Diagnoses were: 33/93 leukaemia (25/33 acute lymphoblastic, $7 / 33$ acute myeloid, 1/33 juvenile myelomonocytic leukaemia); 23/93 iron deficiency anaemia (IDA); 12/93 hereditary blood disorders (including $7 / 12$ hereditary spherocytosis with $6 / 12$ associated parvovirus); $25 / 93$ "other" including $6 / 25$ haemolytic-uraemic syndrome and $3 / 25$ transient erythroblastopaenia. Of leukaemia $5 / 33$ had presenting white cell count $>100 \times 10^{9} / \mathrm{L}$, and all received red-cell transfusion. Of IDA 19/23 had nutritional IDA (nIDA). 17/19 nIDA were aged $<3$ y. 11/17 nIDA were of Pakistani origin (versus $3.5 \%$ of city population). Linking residential postcode with national index of multiple deprivation, 11/17 nIDA lived in the most (lowest 20\%) deprived areas, rising to $9 / 11$ in more severe nIDA $(\mathrm{Hb}<4 \mathrm{~g} / \mathrm{dL})$. In IDA, all were prescribed iron supplementation, 21/23 feeding practises reviewed by dietician and 17/23 were transfused red-cells (all those with $\mathrm{Hb}<4 \mathrm{~g} / \mathrm{dL}$ ). 9/23 IDA resolved within 1y though $3 / 23$ had no repeat $\mathrm{Hb}$ recorded. Of all patients $11 / 93$ died: $3 / 11$ at initial presentation, $6 / 11$ within $1 y$ and $2 / 11$ within $2 y$.

We show that severe anaemia is most commonly caused by acute leukaemia in this population. However nIDA due to poor infant feeding practise is an important preventable diagnosis and may merit particular health education. A disproportionate number of such patients are from deprived areas. A significant number of patients with nIDA had persistent anaemia >1y post presentation suggesting the need for structured follow-up and ongoing intervention.

\section{British Society of Paediatric Gastroenterology, Hepatology and Nutrition/British Paediatric Neurology Association}

\section{G188 THE ROLE OF SCREENING INVESTIGATIONS IN CHILDHOOD ARTERIAL ISCHAEMIC STROKE}

doi:10.1136/archdischild-2013-304107.200

'R Probert, ' $\mathrm{J} \mathrm{Ng}, 1,2 \mathrm{~V}$ Ganesan. ${ }^{1}$ Neurology Department, Great Ormond Street Hospital NHS Foundation Trust, London, UK; ${ }^{2}$ Neurosciences Unit, University College London, Institute of Child Health, London, UK

Childhood arterial ischaemic stroke (AIS) is a heterogeneous disorder, with morbidity in $2 / 3^{\text {rd }}$ of survivors and recurrence in $10 \%$. Current clinical guidelines recommend a wide range of investigations 